\title{
STUDI LITERATUR EFEK MODIFIKASI GAYA HIDUP SECARA INTENSIF PADA PREDIABETES
}

\author{
Serra Meilawati ${ }^{1}$ \\ ${ }^{1}$ Program Pendidikan Dokter Fakultas Kedokteran Universitas Lampung
}

\begin{abstract}
The Effect of Intensive Lifestyle Modification on Prediabetes. Prediabetes is a condition before type 2 diabetes mellitus. Impaired Fasting Glucose (IFG) and Impaired Glucose Tolerance (IGT) are prediabetes. The increasing prevalence of type 2 diabetes mellitus is because every year $4-9 \%$ of people with prediabetes will develop diabetes. IGT has a higher risk of developing to be type 2 diabetes mellitus. So that prevention efforts so that prediabetes does not develop into type 2 diabetes mellitus is very important. Intensive lifestyle modification is an effort that can be done in prediabetes. The Diabetes Prevention Program (DPP) in the United States and the Finnish Diabetes Prevention Study (DPS) conducted clinical trials showing that lifestyle modification is effective in reducing or delaying the onset of type 2 diabetes mellitus by $40-58 \%$ in high-risk individuals. As for lifestyle modifications that can be done, such as weight loss in prediabetes is recommended for $5-10 \%$ of the initial body weight, dietary changes by reducing consumption of simple carbohydrates and increasing consumption of fiber, and physical activity carried out for 30-60 minutes every day. Lifestyle modification intensively in prediabetes has great effectiveness.
\end{abstract}

Keywords : Intensive, Lifestyle modification, Prediabetes

Abstrak: Efek Modifikasi Gaya Hidup secara Intensif pada Prediabetes. Prediabetes adalah kondisi sebelum terjadinya diabetes mellitus tipe 2. Impaired Fasting Glucose (IFG) dan Impaired Glucose Tolerance (IGT) merupakan kondisi prediabetes. Prevalensi diabetes mellitus tipe 2 yang terus meningkat disebabkan karena setiap tahunnya 4-9\% orang dengan prediabetes akan berkembang menjadi diabetes. IGT mempunyai risiko lebih tinggi untuk berkembang menjadi diabetes mellitus tipe 2. Sehingga upaya pencegahan agar tidak berkembangnya prediabetes menjadi diabetes mellitus tipe 2 menjadi sangat penting. Modifikasi gaya hidup secara intensif merupakan upaya yang dapat dilakukan pada prediabetes. Diabetes Prevention Program (DPP) di Amerika Serikat dan Finnish Diabetes Prevention Study (DPS) melakukan uji klinis yang menunjukkan bahwa modifikasi gaya hidup efektif dalam mengurangi atau menunda onset diabetes mellitus tipe 2 sebesar 40$58 \%$ pada individu yang mempunyai risiko tinggi. Adapun modifikasi gaya hidup yang dapat dilakukan seperti, penurunan berat badan pada prediabetes dianjurkan sebesar $5-10 \%$ dari berat badan awal, perubahan pola makan dengan mengurangi konsumsi karbohidrat sederhana dan memperbanyak konsumsi serat, dan aktivitas fisik dilakukan selama 30-60 menit setiap hari. Modifikasi gaya hidup secara intensif pada prediabetes mempunyai efektivitas yang bagus.

Kata Kunci : Intensif, Modifikasi gaya hidup, Prediabetes

\section{PENDAHULUAN}

Prediabetes adalah keadaan dengan kadar glukosa darah di atas normal tetapi belum memenuhi kriteria diagnosis diabetes mellitus. Kondisi yang termasuk prediabetes yaitu, Impaired Fasting Glucose (IFG) dengan kadar glukosa darah setelah puasa sekitar 8-10 jam sebesar $100-125 \mathrm{mg} / \mathrm{dl}$ (5,6-6,9 mmol/L) dan Impaired Glucose 
Tolerance (IGT) dengan kadar gula darah sebesar 140-199 mg/dl (7,8-11 $\mathrm{mmol} / \mathrm{L}$ ) dua jam setelah diberi beban $75 \mathrm{~g}$ glukosa (Dany et al, 2017;Setiawan, 2011). Prediabetes merupakan kondisi sebelum diabetes mellitus terjadi sehingga prediabetes dapat bergerak ke dua arah yaitu, menuju kondisi normal atau kondisi diabetes mellitus (Noventi, Rusdianingseh dan Khafid, 2019).

IFG dan IGT dapat terjadi karena disfungsi sel $\beta$ pankreas yang menyebabkan gangguan metabolisme glukosa. Disfungsi sel $\beta$ pankreas merupakan akibat dari sel $\beta$ pankreas yang terus-menerus mengeluarkan insulin untuk mengompensasi kenaikan kadar glukosa darah akibat dari resistensi insulin. Resistensi insulin adalah kondisi di mana insulin yang dikeluarkan oleh sel $\beta$ pankreas tidak dapat bekerja pada sel target seperti, sel otot, sel lemak dan sel hati sehingga kadar glukosa darah tinggi (Sulistiowati dan Sihombing, 2018).

Prevalensi prediabetes maupun diabetes mellitus tipe 2 di seluruh dunia terus meningkat setiap tahunnya. Pada tahun 2030 diperkirakan $>470$ juta orang akan mengalami prediabetes dan 559 juta orang mengalami diabetes (Tabak et al, 2012; Whiting et al, 2011). Di Indonesia sendiri, menurut Riset Kesehatan Dasar (Riskesdas) 2013 prevalensi prediabetes lebih besar dibandingkkan dengan prevalensi diabetus mellitus tipe 2. Pada tahun 2007 prevalensi IFG sebesar 20,2\% dan IGT sebesar $16,7 \%$ kemudian keduanya mengalami peningkatan pada tahun 2013 dengan IFG sebesar $36,6 \%$ dan IGT sebesar 29,9\% (Khoiriyah, Murbawani dan Panunggal, 2017).

Orang yang mempunyai IFG dan IGT mempunyai risiko tinggi untuk terjadinya diabetes mellitus tipe 2 dalam jangka waktu tertentu (Sulistiowati dan Sihombing, 2018). Setiap tahunnya hampir $4-9 \%$ orang dengan prediabetes akan menjadi diabetes. Menurut data penelitian, IGT memiliki risiko lebih besar untuk terjadinya diabetes mellitus dibandingkan IFG (Noventi,
Rusdianingseh dan Khafid, 2019). Penelitian di Indonesia menunjukkan bahwa prediabetes meningkatkan risiko terjadinya diabetes mellitus tipe 2 sebesar 2-10 kali lipat (Soewondo dan Pramono, 2011).

Prediabetes yang merupakan kondisi yang mengawali terjadinya diabetes mellitus tipe 2 sering terjadi tanpa menunjukkan gejala klinis yang khas diabetes mellitus. Hal tersebut yang menyebabkan prediabetes sulit untuk didiagnosis secara dini dan baru terdiagnosis setelah timbul komplikasi (Erika, Patellongi dan Taiyeb, 2010).

Upaya yang dapat dilakukan agar prediabetes tidak berkembang menjadi daibetes mellitus adalah dengan mengontrol dan mengelola prediabetes menjadi normal. Penelitian yang dilakukan Yolanda (2014) menunjukkan bahwa diabetes dapat dicegah dengan memodifikasi gaya hidup. Hal tersebut didukung dengan prediabetes yang berkembang menjadi diabetes mellitus tipe 2 dalam kurun waktu 3 tahun dapat disebabkan oleh tidak adanya modifikasi gaya hidup (Mayans, 2015).

Penulisan ini bertujuan untuk mereview bagaimana efek modifikasi gaya hidup secara intensif terhadap kejadian prediabetes dari berbagai sumber jurnal dan penelitian terbaru yang relevan.

\section{METODE}

Metode yang digunakan adalah literature searching dengan mengumpulkan data sekunder sesuai dengan yang tertera pada sitasi dan daftar pustaka.

\section{HASIL}

Berdasarkan studi di China, Finland dan Amerika Serikat, terdapat bukti keberhasilan dari modifikasi gaya hidup secara intensif dalam mengurangi risiko berkembangnya diabetes mellitus tipe 2 pada prediabetes. Menurut metaanalisis terbaru, pengurangan risiko diperkirakan sebesar $36 \%$ jika modifikasi gaya hidup secara instensif berlangsung antara 6 bulan dan 6 tahun (Shaw, 2019). Uji coba internasional pada orang dewasa dengan IGT yang 
berpartisipasi dalam program modifikasi gaya hidup menunjukkan $31-58 \%$ pengurangan untuk berkembangan menjadi diabetes mellitus tipe 2 (Handayani, 2012). Bukti uji klinis berskala besar seperti Diabetes Prevention Program (DPP) di Amerika Serikat dan Finnish Diabetes Prevention Study (DPS) menunjukkan bahwa intervensi modifikasi gaya hidup efektif dalam mengurangi atau menunda onset diabetes mellitus tipe 2 sebesar $40-58 \%$ pada individu yang mempunyai risiko tinggi seperti mempunyai prediabetes (Ibrahim, 2011).

Modifikasi gaya hidup dalam mencegah berkembangnya prediabetes menjadi diabetes mellitus tipe 2 dapat berupa perubahan pola makan, aktivitas fisik dan penurunan berat badan. Menurut National Institute of Health Diabetes Prevention Program (NIH-DPP) penundaan timbulnya diabetes mellitus tipe dua terkait dengan penurunan berat badan sederhana dan peningkatan aktivitas fisik yang signifikan (Handayani, 2012). Penelitian pada orang cina yang mengalami IGT juga menunjukkan bahwa intervensi gaya hidup berupa diet dan/ olahraga dalam jangka waktu yang lama secara signifikan menurunkan insidensi diabetes (Mirasol et al, 2017).

Hasil penelitian di Indonesia menunjukkan terdapat hubungan yang bermakna antara aktivitas fisik dengan prediabetes maupun kadar gula darah. Semakin tinggi aktivitas fisik maka semakin rendah kadar gula darah (Astuti, 2019;Vidyanto dan Arifuddin, 2019). Pada individu yang melakukan intevensi gaya hidup berupa diet dan aktivitas fisik selama 6 tahun menghasilkan berkurangnya risiko berkembangnya prediabetes menjadi diabetes sebesar masing-masing 31\% dan 46\%. Diabetes Prevention Program (DPP) di Amerika Serikat melakukan uji klinis terkontrol acak yang menunjukkan hasil bahwa insidensi diabetes pada grup yang diberi intervensi gaya hidup lebih rendah dibandingkan grup placebo pada orang dewasa dengan IGT dan/ IFG (dengan rata-rata BMI $34.0 \mathrm{~kg} / \mathrm{m}^{2}$ dan rata-rata usia 51 tahun). Sehingga dapat disimpulkan bahwa satu kasus diabetes dapat dicegah dengan merawat 7 pasien dengan modifikasi gaya hidup intensif selama 3 tahun (Mirasol et al, 2017).

\section{PEMBAHASAN}

Berdasarkan hasil penelitian di atas, modifikasi gaya hidup dapat dijadikan sebagai pendekatan manajemen fundamental yang bisa secara efektif mencegah perkembangan prediabetes menjadi diabetes. Modifikasi gaya hidup yang dapat dilakukan adalah perubahan pola makan, aktivitas fisik dan penurnan berat badan (Handayani, 2012).

Perubahan pola makan dapat dilakukan dengan cara pemilihan makanan yang tepat dan sehat salah satunya adalah mengonsumsi secara tidak berlebihan asupan karbohidrat sederhana baik glukosa, sukrosa, fruktosa atau kombinasi ketiganya. Asupan fruktosa secara akut dapat menyebabkan terjadinya resistensi insulin sehingga dapat meningkatkan kejadian diabetes mellitus tipe 2 . Salah satu mekanisme resistensi insulin akibat asupan fruktosa adalah adanya peningkatan konsentrasi lemak ke hati yang kemudian menyebabkan peningkatan zat metabolit asam lemak seperti diasilgliserol, asil KoA dan seramid. Zat metabolit inilah yang menyebabkan berkurangnya fosforilasi PI-3 kinase yang terlibat dalam transport glukosa melalui aktivasi protein kinase $\mathrm{C}$ dan peningkatan fosforilasi IRS-1 Ser307 sehingga terjadi penurunan sensitivitas reseptor insulin dan gangguan transport glukosa (Khoiriyah, Murbawani dan Panunggal, 2017).

Perubahan pola makan yang lain adalah dengan mengonsumsi serat. Serat dapat menurunkan risiko terjadinya diabetes mellitus tipe 2 dengan cara mikrobiota usus besar menjadikan serat sebagai substrat untuk membentuk asam lemak rantai pendek seperti asetat. Asam lemak rantai pendek inilah yang akan diserap ke dalam peredaran darah yang kemudian menekan pelepasan asam 
lemak bebas dari jaringan adiposa sehingga menurunkan asam lemak bebas yang beredar yang akhirnya akan membuat sensitivitas insulin meningkat (Khoiriyah, Murbawani dan Panunggal, 2017).

Aktivitas fisik dapat secara langsung memengaruhi seberapa banyak otot menyerap glukosa dari pembuluh darah dengan meningkatkan sensitivitas insulin. Glukosa yang tersimpan dalam otot akan digunakan saat beraktivitas fisik karena pada saat itu gerakan dapat ditimbulkan dari kontraksi otot. Kontraksi otot dihasilkan dari pemecahan gula yang kemudian diubah menjadi energi. Otot akan menyerap glukosa dari pembuluh darah jika glukosa sudah berkurang. Sehingga glukosa dalam darah akan menurun dan mampu mempertahankan glukosa darah tetap normal. Aktivitas fisik dapat dilakukan seperti berjalan, berlari, berolahraga, latihan aerobik, bersepeda dan lain-lain (Sukenty, Shaluhiyah dan Suryoputro, 2018; Kristanti, 2016).

Aktivitas fisik pada prediabetes dianjurkan olahraga selama 20 menit/hari yang dilakukan 3 hari dalam seminggu (Kristanti, 2016). Aktivitas fisik berupa latihan aerobik dapat dilakukan minimal 150 menit setiap minggu (Setyowati dan Quyumi, 2018). Terdapat bukti bahwa insidensi diabetes lebih rendah pada kelompok yang melakukan latihan aerobik dengan berjalan sebanyak 10.000 langkah setiap hari (Erika, Patellongi dan Taiyeb, 2010). Menurut Indonesia Diabetes Association (2014) aktivitas fisik yang direkomendasikan adalah aktivitas fisik berintensitas sedang dengan durasi 3060 menit setiap hari paling tidak 4 hari dalam seminggu atau minimal 150 menit setiap minggu.

Salah satu faktor risiko terjadinya diabetes mellitus tipe 2 adalah obesitas. Pada obesitas Body Mass Index (BMI)nya adalah sekitar $>25 \mathrm{~kg} / \mathrm{m}^{2}$. Orang yang mempunyai obesitas memiliki timbunan asam lemak bebas yang akan menyebabkan terikatnya oksidasi lemak dan kemudian menghambat penggunaan glukosa sehingga terjadilah penurunan sensitivitas insulin (Astuti, 2019). Penurunan berat badan tingkat sedang hasilnya dapat mengurangi kadar glukosa. Selain itu, dapat juga mengurangi kadar tekanan darah, kadar low density lipoprotein (LDL) dan kadar trigliserida. Diabetes Prevention Program (DPP) menganjurkan pengurangan berat badan sebesar 5$10 \%$ dari berat badan awal pada orang prediabetes dan mempertahankannya dalam jangka waktu yang lama (Indonesia Diabetes Association, 2014).

\section{SIMPULAN}

Pada orang yang memiliki prediabetes dapat diberikan intervensi berupa modifikasi gaya hidup untuk mencegah atau menunda berkembangnya prediabetes menjadi diabetes mellitus tipe 2 . Modifikasi gaya hidup secara intensif sebagai intervensi pada prediabetes terbukti mempunyai efektivitas yang bagus.

\section{DAFTAR PUSTAKA}

Astuti, A. (2019). Usia, Obesitas dan Aktivitas Fisik Beresiko Terhadap Prediabetes. Jurnal Endurance: Kajian Ilmiah Problema Kesehatan. 4(2): 319-324.

Dany F, Kusumawardani N, Pradono J, Kristianto Y, \& Delima. (2017). Faktor Risiko Prediabetes: Isolated Impaired Fasting Glucose (i-IFG), Isolated Impaired Glucose Tolerance (i-IGT) dan Kombinasi IFG-IGT (Analisis Lanjut Riskesdas 2013). Buletin Penelitian Kesehatan. 45(2): 113-124.

Erika KA, Patellongi I, \& Taiyeb MA. (2010). Peranan Lifestyle Terhadap Kejadian Pra-Diebetes di Kota Makassar. Bionature. 11(2): 100106

Handayani. (2012). Modifikasi Gaya Hidup dan Intervensi Farmakologis Dini Untuk Pencegahan Penyakit Diabetes Mellitus Tipe 2. Media Gizi Masyarakat Indonesia. 1(2): 65-70.

Ibrahim, N. (2011). A CommunityBased Healthy Lifestyle Intervention Amongst High Risk Individuals to Prevent Diabetes (Co-HELP)-A 
Translational Research. Research Protocol.

Khoiriyah D, Murbawani EA, \& Panunggal B. (2017). Asupan Karbohidrat dan Aktivitas Fisik Dengan Prediabetes Pada Wanita Dewasa. Preventif: Jurnal Kesehatan Masyarakat. 8(2): 5965.

Mayans L. (2015). Metabolic Syndrome: Insulin Resistance and Prediabetes. Journal pubmed. 435: 11-17.

Mirasol R, Thai AC, Salahuddin AA, Tan $\mathrm{K}$, Deerochanawong $\mathrm{C}$, Mohamed $\mathrm{M}$, Saraswati MR, Sethi BK, Shahs S, Soetedjo NN, Suraamornkul S, Tan R, \& Uddin F. (2017). A Consensus of Key Opinion Leaders on the Management of Pre-Diabetes in the Asia-Pacific region. Journal of the ASEAN Federation of Endocrine Societies. 32(1):6-12.

Noventi I, Rusdianingseh, \& Khafid M. (2019). Prevalensi, Karakteristik dan Faktor Resiko Prediabetes di Wilayah Pesisir, Pegunungan dan Perkotaan. Jurnal Ners dan Kebidanan. 6(3): 371-381.

Setiawan M. (2011). Pre-Diabetes dan Peran HBA1C Dalam Skrining dan Diagnosis Awal Diabetes Mellitus. 7(14): 57-64.

Setyowati N, \& Quyumi E. (2018). Kejadian Prediabetes Pada Usia Dewasa di Wilayah Puskesmas Sukorame Kota Kediri. Seminar Nasional Penelitian dan Pengabdian Masyarakat. 3: 258-260.

Shaw JE. (2019). Prediabetes: Lifestyle, Pharmacotherapy or regulation?. Therapeutic Advances in Endocrinology and Metabolism. 10: 1-6.

Soewondo, \& Pramono LA. (2011). Prevalence, Characteristics, and
Predictor of Diabetes in Indoneisa. Medical Journal Indonesia. 20(4) 283-294.

Sukenty NT, Shaluhiyah Z, \& Suryoputro A. (2018). Faktor Perilaku dan Gaya Hidup yang Mempengaruhi Status Prediabetes Pasien Puskesmas Pati II. Jurnal Promosi Kesehatan Indonesia. 13(2): 129-142.

Sulistiowati E, \& Sihombing M. (2018). Perkembangan Diabetes Mellitus Tipe 2 Dari Prediabetes di Bogor, Jawa Barat. Jurnal Penelitian dan Pengembangan Pelayanan Kesehatan. 2(1): 59-69.

Tabak AG, Herder C, Rathmann W, Brunner EJ, \& Kivimaki M. (2012). A High-Risk State For Developing Diabetes. Lancet. 379(9833): 22792290.

The Indonesian Diabetes Association. (2014). Guidelines on the Management and Prevention of Prediabetes. The Indonesian Journal of Internal Mmedicine. 46(4): 348359.

Vidyanto, \& Arifuddin A. (2019). Determinan Peningkatan Kadar Gula Darah Pasien Interna Rumah Sakit Umum (RSU) Anutapura Palu. Jurnal Kesehatan Tadulako. 5(1): 58-62.

Whiting DR, Guariguata L, Weil C, \& Shaw J. (2011). IDF Diabetes Atlas: Global Estimates of the Prevalence of Diabetes For 2011 and 2030. Diabetes Research and Clinical Practice. 94(3): 311-321. 